\title{
Novas perspectivas na gestão do saneamento: apresentação de um modelo de destinação final de resíduos sólidos urbanos
}

\author{
New perspectives on sanitation management: proposing a model for municipal \\ solid waste landfill
}

Cristina Maria Dacach Fernandez Marchi

Universidade Católica do Salvador (UCSAL), Salvador, BA, Brasil

\section{Resumo}

A complexidade que envolve a prestação dos serviços públicos de coleta, tratamento e destinação final de resíduos sólidos, as dimensões que a questão assume face às diversas repercussões sociais, governamentais, territoriais e técnicas e o seu potencial de alteração qualitativa do meio ambiente conduzem a um estudo mais aprofundado da gestão dos aterros e suas inter-relações com as instituições ligadas aos resíduos sólidos e à gestão das cidades. A questão que norteou este trabalho foi: o desenvolvimento de um modelo para instalação de equipamentos de destinação final dos resíduos sólidos, que envolva aspectos ambientais e de gestão, pode atender as especificidades, particularidades, de diferentes municípios? A metodologia adotada foi o estudo multicasos descritivo e exploratório. Quanto aos procedimentos sistemáticos para a descrição e explicação dos eventos encontrados, o estudo se desenvolveu num ambiente que preconizou a abordagem quantiqualitativa. Conclui-se com a apresentação e a definição das atividades de um Modelo para Instalação e Gestão de Equipamentos de Destinação Final dos Resíduos Sólidos. Tratou-se de um processo de construção teórica e metodológica que partiu de perguntas e gerou novas questões, especialmente quanto à forma de mensurar e analisar possíveis mudanças comportamentais em saneamento básico, em função das posturas e procedimentos inovadores difundidos em todo o país pela Política Nacional de Resíduos Sólidos.

Palavras-chave: Resíduos sólidos. Planejamento urbano. Gestão municipal. Modelo para destinação final de resíduos sólidos.

\section{Abstract}

The complexity involved in the collection, treatment and disposal of solid waste; the dimensions of this matter in relation to the various social, governmental, technical and territorial implications, and their potential for qualitative change of the environment require further studies of the management of landfills and their inter-relations with institutions linked to solid waste and the environment. The key question of this paper is: Would the development of a protocol for the installation of solid-waste disposal equipment, involving both environmental and management aspects, suit the specific needs and peculiarities of different municipalities? An explanatory and descriptive multi-case study was used to evaluate the technologies applied in the deployment and management of two landfills in the state of Bahia. A protocol for the management and installation of solid-

CMDFM é Administradora, mestre em Análise Regional, doutora em Geologia Ambiental, e-mail: cmmarchi@gmail.com 
waste equipment was also designed in this study, based on a theoretical and methodological construction that originated from questions that have also generated news questions and issues, such as how to measure and analyze possible behavioral changes towards sanitation according to the innovative procedures proclaimed throughout the country by the National Solid Waste Policy.

Keywords: Solid waste policy. Urban planning. Municipal management. Landfill management model.

\section{Introdução}

A crise ambiental vivenciada no mundo tem se constituído em um dos maiores desafios da humanidade. 0 aumento da poluição e a utilização predatória das riquezas naturais têm acelerado o aquecimento global causado pelo efeito estufa e a destruição das florestas e dos rios. Contudo, a problemática não se resume ao contexto ecológico, mas também permeia o contexto social. As dificuldades de natureza social e ecológica são indissociáveis, apesar de muitas vezes serem tratadas de forma isolada.

Nas duas últimas décadas, o padrão de comportamento social e institucional vem sendo modificado, principalmente por razões de ordem cultural, intervindo no cotidiano social e ambiental, necessitando de novos investimentos em saneamento básico, notadamente em locais destinados à disposição dos Resíduos Sólidos Urbanos - RSU.

As práticas inadequadas de saneamento básico fomentam a deterioração ambiental e mobilizam o Estado a implantar novas tecnologias, além de enfatizar ações educativas, visando reduzir o desequilíbrio existente no meio ambiente e criar facilidades à incorporação de novas práticas, que proporcionem maior qualidade de vida.

A gestão da área de saneamento básico é, antes de tudo, uma questão de sobrevivência, tanto para a sustentabilidade do meio ambiente quanto das instituições e organizações que o cercam. Isso faz com que a variável ambiental esteja presente no planejamento das organizações, pelo fato de oportunizar redução de custos, já que a poluição significa o desperdício de matéria-prima e insumos, além de afastamento de novos investimentos.

A complexidade que envolve a prestação dos serviços públicos de coleta, tratamento e destinação final de resíduos sólidos, as dimensões que a questão assume face às diversas repercussões sociais, governamentais, territoriais e técnicas, e o seu potencial de alteração qualitativa do meio ambiente necessitam de estudo mais aprofundado da gestão dos aterros e suas inter-relações com as instituições ligadas aos resíduos sólidos e ao meio ambiente.

0 crescimento populacional, a consequente expansão territorial urbana, a ampliação do sistema de produção e consumo industrial têm contribuído para agravar as condições ambientais. A forma precária que vêm sendo avaliados os aterros sanitários baianos, tanto no que refere à gestão quanto aos impactos ambientais, sinaliza a necessidade de investigação acurada. 0 objetivo geral deste trabalho inclui essa preocupação, visto que busca analisar quais instrumentos de gestão podem provocar ampliação e melhoria no atendimento da destinação final de resíduos sólidos, e a consequente prevenção da poluição ambiental.

O estudo em questão procura ser congruente com a ideia de sustentabilidade ambiental e organizacional de equipamentos públicos de destinação final nos centros urbanos. $\mathrm{O}$ questionamento norteador foi: o desenvolvimento de um modelo para instalação de equipamentos de destinação final dos resíduos sólidos, que envolva aspectos ambientais e de gestão, pode atender as especificidades, particularidades, de diferentes municípios?

\section{Arcabouço legal e conceituação dos resíduos sólidos no Brasil}

O Gerenciamento Integrado de Resíduos Sólidos é a coparticipação no sistema de limpeza urbana (acondicionamento, coleta, triagem e reciclagem, transporte, tratamento e destinação final dos rejeitos). Envolve diferentes órgãos da administração pública, das organizações e da sociedade civil, objetivando elevar a qualidade de vida da população e promover o desenvolvimento sustentável. Um instrumento que apoia o gerenciamento integrado 
de resíduos sólidos é o Plano de Gerenciamento Integrado de Resíduos Sólidos (PGIRS), documento que diagnostica a situação atual e traça cenários para o sistema de limpeza urbana. Esse documento deve estabelecer diretrizes e ações ligadas aos aspectos ambientais, econômicos, financeiros, administrativos, técnicos, sociais e legais, desde a geração até a destinação final dos resíduos sólidos. Ações e diretrizes que devem se processar de modo articulado, porque as atividades e procedimentos envolvidos nesse componente do saneamento básico encontram-se interligados, comprometidos entre si.

A interligação entre essas diferentes esferas necessita de instrumentos legais que a fundamente. Desde o final dos anos 70, as legislações federais que vêm atuando como ferramenta de apoio na interrelação entre resíduos sólidos, sociedade e meio ambiente são:

1. A Lei n. 6.766 (Brasil, 1979), que define as competências do Estado e do Município sobre a questão do parcelamento do solo.

2. A Lei n. 6.938 (Brasil, 1981), regulamentada pelo Decreto n. 99.274/1990, que define a política nacional do meio ambiente e regula a estrutura administrativa de proteção e de planejamento ambiental, o Sistema Nacional do Meio Ambiente (Sisnama).

3. A Constituição da República Federativa do Brasil de 1988 (Brasil, 1988), que estabelece os princípios da política nacional do meio ambiente.

4. A Resolução Conama n. 5 (Brasil, 1993), que dispõe sobre o tratamento de resíduos sólidos gerados em estabelecimentos de saúde, portos e aeroportos e terminais ferroviários e rodoviários.

5. A Lei n. 9.605 (Brasil, 1998) que dispõe sobre as sanções penais e administrativas derivadas de condutas e atividades lesivas ao meio ambiente, e dá outras providências.

6. A Lei n. 11.445 (Brasil, 2007), que estabelece as diretrizes nacionais para o saneamento básico e a política federal de saneamento básico.

7. O Decreto n. 7.217 (Brasil, 2010a), que regulamenta a Lei n. 11.445/2007 e estabelece normas para sua execução.

8. A Lei n. 12.305 (Brasil, 2010c), que institui a Política Nacional de Resíduos Sólidos.
9. O Decreto n. 7.404 (Brasil, 2010b), que regulamenta a Lei n. 12.305/2010.

10. A Lei n. 12.932 (Brasil, 2014b), que institui na Bahia a Política Estadual de Resíduos Sólidos.

11. 0 Decreto n. 8.211 (Brasil, 2014a), que altera o Decreto n. 7.217, de 21 de junho de 2010, que regulamenta a Lei n. 11.445, de 5 de janeiro de 2007.

Os marcos relativos aos itens seis e oito merecem destaque. A Lei n. 11.445 (Brasil, 2007), que estabelece as diretrizes nacionais para o saneamento básico e a Política Federal de Saneamento Básico, resultado de décadas de debates, exige legalmente a ação de planejamento. Na lei cabe ao titular dos serviços públicos de saneamento básico formular a política pública de saneamento básico, ação indelegável a outro ente, devendo para tanto elaborar o plano de saneamento básico (art. 9o-, do Capítulo II). A participação da sociedade na elaboração do plano é assegurada no parágrafo 5 , inciso $\mathrm{V}$, do art. 19, do Capítulo IV e no art. 51 do Capítulo IX (Brasil, 2007). Esse marco regulatório também prevê, com consultas e audiências públicas, o acesso por todos, aos estudos e às informações. Assim, não só a ação de planejamento se constitui em um desafio, mas também a promoção de um planejamento participativo.

Outra importante norma para a área é a Lei n. 12.305 (Brasil, 2010c), que instituiu a Política Nacional de Resíduos Sólidos, discutida desde 1991 pelo Congresso Nacional. Esse regulamento impõe obrigações aos empresários, ao poder público e aos cidadãos no gerenciamento dos resíduos sólidos. Esse marco regulatório busca reforçar e incentivar o consumo consciente e o combate ao desperdício. Estimula a pesquisa, as tecnologias sustentáveis e o controle social. Reconhece também a ação dos catadores de materiais recicláveis, como a força motriz da coleta seletiva, seja ela de caráter formal ou não.

\section{Estrutura e procedimentos de gestão na destinação final dos RSU}

É inevitável a geração de resíduos sólidos nas cidades devido à cultura do consumo. 0 sistema de limpeza urbana deve estar preparado para ser 
administrado por meio de diversas estruturas organizacionais, seja pela administração direta do município, por uma empresa pública específica, por uma empresa de economia mista, criada para desempenhar especificamente essa função, por concessões, terceirizações ou consórcio com outros municípios, especialmente para a destinação final dos RSU. 0 uso de instrumentos gerenciais, como planejamento técnico, operacional e gerencial, administração dos recursos humanos, patrimoniais e financeiros, organização das tarefas, direção das atividades e controle de todo o sistema de limpeza urbana, permite a criação de procedimentos e rotinas que contribuem para um manejo apropriado dos RSU.

Esses procedimentos e rotinas enfocam desde o planejamento integrado dos sistemas de limpeza urbana, com a elaboração dos Planos de Gestão de Limpeza Urbana (PGLU), até a sua implementação ou ainda construção de aterros sanitários, recuperação de áreas degradadas por "lixões", programas de educação ambiental, capacitação do pessoal operacional e projetos de ressocialização dos catadores dos "lixões".

0 aterro sanitário é um equipamento projetado para receber e tratar os RSU gerados pelos habitantes de uma cidade, com base em estudos de Engenharia e Geologia, visando reduzir ao máximo os impactos causados ao meio ambiente. 0 aterro sanitário constitui-se em uma das técnicas mais seguras e de mais baixo custo para destinação final de RSU (UNEP \& IETC, 2005; SYCTOM, 2008). São projetados para uma vida útil superior a 10 anos, prevendo-se ainda a sua monitorização alguns anos após o seu fechamento. Os aterros sanitários são projetados e construídos em conformidade com a legislação vigente, após estudos de impacto ambiental (EIA) e processo de licenciamento.

Diferentemente dos aterros sanitários, nos quais são empregados procedimentos e cuidados para uma disposição adequada dos RSU sobre o solo, os aterros controlados dispõem os RSU sem proteger a área utilizada para esse fim. Contudo, $o$ aterro considerado como controlado utiliza alguns mecanismos para minimizar os impactos ao solo, como: disposição ordenada, compactação dos RSU e cobertura com uma camada de terra. Pode ainda apresentar algum controle para evitar a poluição do lençol freático.

Os "lixões" consistem na disposição inadequada dos RSU em áreas baldias, afastadas da cidade e sem qualquer cuidado com o uso do solo. Não existem medidas de proteção à saúde pública, tampouco ao meio ambiente. A disposição inadequada de RSU no solo, com a consequente contaminação das águas superficiais, é reconhecidamente um dos graves problemas da atualidade (UNEP \& IETC, 2005; USEPA, 1996). Os efeitos do lançamento de rejeitos na natureza são incalculáveis e recaem principalmente na escassez, na contaminação da água e no aumento das doenças associadas à poluição ambiental.

Outras destinações dadas aos RSU são: a redução, a reutilização e a reciclagem, ferramentas gerenciais que ajudam a diminuir o volume de resíduos urbanos e industriais que seguiriam para os aterros sanitários. Essas ferramentas se encontram inseridas na Política Nacional de Resíduos Sólidos.

Gerir os RSU de uma maneira integral significa limpar o município e processar os resíduos sólidos, utilizando as tecnologias mais compatíveis à realidade local, dando-se destinação final ambientalmente segura.

Para Nunesmaia (2002), a gestão integrada traduz a necessidade de harmonizar políticas públicas, de definir normas comuns, de lutar contra medidas discriminatórias, de suprimir disparidades existentes, de estabelecer hierarquia dos princípios da gestão de RSU, de conceber várias linhas tecnológicas de valoração e de eliminação dos resíduos sólidos, de fortalecer cooperações intermunicipais, de financiar os serviços, de proporcionar forte participação da população na definição de prioridades no modelo de gestão, no controle e no acompanhamento e de integrar os RSU às preocupações relativas às atividades econômicas, ao emprego, à autonomia e ao desenvolvimento sustentável.

0 gerenciamento municipal é o maior problema para a melhoria da área de RSU no Brasil. Pessoal inadequado, equipamentos danificados e obsoletos, recursos escassos e mal aplicados são problemas municipais constantes, com alguma exceção nas capitais dos estados mais desenvolvidos.

Moraes \& Borja (2009) divulgam os seguintes determinantes para a inadequada gestão dos RSU na maioria dos municípios brasileiros: (1) limitações de ordem financeira, como orçamentos inadequados, fluxo de caixas desequilibrados, taxas desatualizadas, quando existe, arrecadação insuficiente e inexistência de linha de crédito específica; (2) pouca capacidade institucional; (3) deficiência na capacitação 
técnica e profissional do gari ao engenheiro-chefe; (4) descontinuidade política e administrativa; (5) uso de tecnologias inadequadas às realidades institucional e operacional, à disponibilidade de recursos humanos e financeiros e aos aspectos de ordem sociocultural; (6) falta de programas de educação ambiental; (7) pouco envolvimento da sociedade com a problemática dos resíduos sólidos; e (8) ausência de controle ambiental.

As diretrizes nacionais são de cumprimento obrigatório dos agentes públicos e privados com atuação na área. Há na legislação, instrumentos jurídicos para auxiliarem os municípios na gestão dos RSU. A Lei n. 11.445 (Brasil, 2007) orienta a participação do governo federal junto aos órgãos pertinentes, para o desenvolvimento das ações de abastecimento de água, esgotamento sanitário, drenagem urbana e resíduos sólidos.

Esse marco legal vem trazendo nova perspectiva à população que sofre da falta de saneamento básico. O Capítulo VIII trata da Participação de Órgãos Colegiados no Controle Social e afirma que as diversas esferas de governo, o setor privado e organizações não governamentais podem promover ações e programas de urbanização, de habitação, de saneamento básico e ambiental, transporte urbano, trânsito e desenvolvimento, proporcionando um caminho para o enfrentamento desse grande desafio, que é a justa distribuição dos serviços públicos de saneamento básico a toda população das cidades brasileiras.

Daí se ter considerado e dado destaque também à limpeza urbana e ao manejo de resíduos sólidos, que apresentam, de certa forma, um quadro diferenciado dos serviços públicos de água e esgoto, no que tange à relação que mantém a sociedade civil com as operadoras desses serviços e os órgãos municipais gestores da limpeza urbana.

Em 7 de janeiro de 2014 (Brasil, 2014b), o governo do Estado da Bahia sancionou a Política Estadual de Resíduos Sólidos (PERS/BA), que é semelhante à política nacional. 0 objetivo desse marco regulatório é estabelecer uma política estadual de gestão dos RSU, cuja prioridade é, além de reduzir a geração dos resíduos sólidos na fonte, implantar um programa consistente de educação ambiental.

Com os instrumentos que os procedimentos educacionais possuem, a população poderá participar mais efetivamente dos serviços públicos de limpeza urbana, embora o gerenciamento dos RSU de uma municipalidade seja de responsabilidade da administração direta municipal, ficando geralmente os serviços sob a responsabilidade de variados órgãos da prefeitura.

O poder público não consegue acompanhar com eficiência o aumento da geração de resíduos sólidos nos centros urbanos, a agilidade em sanar problemas técnicos e operacionais. Em muitos casos, resta terceirizar serviços que seriam da competência da administração direta.

A falta de cultura da gestão dos RSU, a incipiente estrutura da Administração Pública municipal, a baixa arrecadação das receitas tributárias próprias e, por fim, a falta de instrumentos que respaldem o exercício de atividades gerenciais na esfera municipal agravam o controle dos serviços realizados por terceiros.

A Política Nacional de Resíduos Sólidos, Lei n. 12.305 (Brasil, 2010c), vem apoiar o caminho a ser trilhado para a universalização dos serviços públicos de limpeza urbana no Brasil. Essa lei preconiza que a responsabilidade pela coleta, tratamento e destinação final dos resíduos sólidos seja compartilhada entre poder público, empresas e consumidores. No Capítulo IV, relativo ao fluxo dos resíduos sólidos, a lei dispõe que os resíduos sólidos deverão ser reaproveitados em produtos na forma de novos insumos, em seu ciclo ou em outros ciclos produtivos, cabendo ao consumidor, ao titular dos serviços públicos, ao fabricante e aos comerciantes o comprometimento no exercício das suas funções para obter sucesso na sua aplicação (Brasil, 2010c). Por exemplo, os resíduos sólidos reversos, coletados pelo poder público, deverão ser disponibilizados em instalações ambientalmente adequadas e seguras, para que as empresas providenciem o retorno para o ciclo produtivo.

Não é suficiente unicamente se investir em serviços públicos com tecnologias apropriadas, mas é necessário dotar os gestores de canais e ferramentas que tragam novas práticas e posturas, criando, dessa forma, uma nova cultura para o gerenciamento desses serviços.

No Brasil, o modelo de gestão de consórcios intermunicipais é recente. É um modelo baseado no ganho de eficiência na gestão e na execução das políticas e despesas públicas entre serviços comuns 
dos municípios associados, geralmente operados por uma empresa privada da área de saneamento básico.

O cenário precário do manejo dos RSU no Brasil ressalta a necessidade de um esforço maior na direção de um gerenciamento mais efetivo e eficaz nas instituições que administram os locais reservados para destinação final dos RSU. Novas tecnologias, metodologias e, sobretudo, capacitação de recursos humanos tornam-se urgentes nessa área.

\section{Fundamentos teóricos}

Este estudo tomou por base dois eixos temáticos do desenvolvimento urbano no Brasil: o do planejamento e o da gestão municipal, interligandoos com o gerenciamento da destinação final dos RSU.

\section{Planejamento urbano e planejamento} estratégico municipal

Adotando o estudo de Pfeiffer (2000) como modelo explicativo sobre a mudança do contexto municipal brasileiro desde a Constituição de 1988, ações mais vigorosas e novas competências são necessárias para o trabalho de implementação das políticas públicas devido à transferência de gestão e de encargos do governo central para o local. Os municípios não se aparelharam para tanto, a transferência de responsabilidades não foi acompanhada pela preparação e fortalecimento dos municípios, já que as prefeituras não possuem condições organizacionais, técnicas e administrativas para aproveitar a autonomia adquirida, além de enfrentar a globalização, que vem trazendo mudanças na estrutura econômica do Brasil, competição entre os municípios e terceirização de serviços (Pfeiffer, 2000). Esses fatores vêm estimulando a governança pública a adotar novas práticas de desenvolvimento urbano, práticas estas que respondam a um gerenciamento moderno e dinâmico, que sejam capazes de lidar adequadamente com as influências externas.

Tais influências vêm trazendo incertezas aos gestores municipais, incertezas que implicam na adoção de uma dinâmica permanente de planejamento, execução, monitoramento, avaliação e ajustes. 0 planejamento abrange decisões e escolhas de alternativas em torno da análise e leituras de cenários que envolvam fatores culturais, sociais, econômicos, ambientais, políticos, dentre outros. 0 planejamento pode ser entendido como processo para determinar ações futuras, através de uma sequência de escolhas (Davidoff \& Reiner, 1973 apud Saboya, 2013).

Pfeiffer (2000) considera planejamento como a definição deliberada e intencional de objetivos e das ações necessárias para o alcance desses objetivos.

Não é tarefa fácil a tomada de decisões do gestor público, visando à adoção de novas práticas. No trabalho de Saboya (2013), a decisão é entendida como um processo de consideração e reflexão sobre uma situação problemática, a escolha de caminhos possíveis, bem como o alcance de uma conclusão com relação ao curso das futuras ações. Entretanto, é frágil a convicção de que determinadas deliberações darão o resultado esperado. No caso de processos decisórios participativos, constante atenção e conhecimento das condições sob as quais a convicção aparece podem auxiliar a tomada de decisões sem distorções ou com efeitos negativos minimizados.

Nesse processo de deliberações, Saboya (2013) propõe uma classificação das decisões relevantes para o planejamento urbano: 1 - Decisões de primeira ordem: decisões executivas, são aquelas que acontecem quando são tomadas por um ator que se compromete e empreende todos os esforços para que sejam efetivadas; 2 - Decisões de segunda ordem: decisões substantivas, são aquelas que envolvem o conteúdo do plano (estratégias, programas, ações, normas reguladoras) e definem onde se quer chegar (objetivos); e 3 - Decisões de terceira ordem: decisões vinculadas aos aspectos processuais, são aquelas que apresentam as condições sob as quais as decisões de segunda ordem serão tomadas. 0 autor afirma que os estudos ligados à teoria do planejamento encontram suporte nos aspectos processuais ligados às decisões de terceira ordem.

No Brasil, a Constituição da República Federativa do Brasil de 1988 (Brasil, 1988) previu instauração da função social da cidade, tratando da política urbana e de uma série de instrumentos de planejamento, visando garantir no âmbito de cada município o direito à cidade, a defesa da função social da cidade, a propriedade e a democratização da gestão urbana. A Lei n. 10.257 (Brasil, 2001) 
- Estatuto da Cidade contempla um conjunto de princípios e uma série de instrumentos que permitem a construção participativa de cidades sustentáveis e democráticas. Dentro do texto do Estatuto das Cidades foi criado o Plano Diretor de Desenvolvimento Urbano (PDDU), que preserva o caráter municipalista e dá ênfase à gestão participativa. 0 PDDU é obrigatório para todas as cidades brasileiras com mais de 20 mil habitantes e visa favorecer a discussão e a apresentação de soluções e projetos para os problemas das cidades.

Pfeiffer (2000) acredita que, como foi concebido, o Plano Diretor das Cidades se configura como instrumento primordialmente político, enquanto o desenvolvimento das cidades ocorre independente dele. Este autor aponta o Planejamento Estratégico como uma das práticas administrativas que pode lidar adequadamente com processos dinâmicos de mudanças e transformações para o setor público. O autor apresenta o Planejamento Estratégico Municipal - PEM como um método que integra a filosofia e alguns dos instrumentos do Planejamento Estratégico com as necessidades específicas de planejamento municipal. A aplicação da técnica de Planejamento Estratégico, amplamente utilizada no setor privado, auxilia as organizações, mesmo as públicas, a direcionarem suas forças internas para que trabalhem na mesma direção, bem como a analisarem o ambiente externo, buscando lidar de forma apropriada com situações complexas. Esse esforço tem como base o diagnóstico "cuja apresentação muitas vezes já é tida como plano. Dessa forma são elaborados inúmeros planos" (Pfeiffer, 2000, p. 9). 0 PEM pode ser formatado com vistas a atender as distintas dinâmicas inseridas nos serviços dos RSU.

Nos Estados Unidos, o estudo realizado por $\mathrm{Ai}$ (2011) demonstra que a geração de resíduos pode ser dissociada do crescimento da população urbana quando estratégias de gestão são planejadas e bem-sucedidas. 0 autor fundamenta seus estudos nas teorias de planejamento voltadas para o interesse público. Apresenta o processo interativo de planejamento racional, baseado nos estudos de Simon (1945 apud Ai, 2011, p. 30) e de Meyerson \& Banfield (1955 apud Ai, 2011, p. 30), no qual os planejadores estabelecem o objetivo do plano, identificam os problemas atuais e possíveis alternativas para solucioná-los, determinam as variáveis para avaliar as opções encontradas e, finalmente, implementam as alternativas selecionadas que responderão aos objetivos propostos. A avaliação constante se encontra presente neste processo interativo, ilustrado na Figura 1.

A perspectiva de planejamento urbano com o objetivo de atender os interesses públicos remete aos territórios e à busca de participação da população, como garante a Lei n. 11.445 (Brasil, 2007), que estabelece as diretrizes nacionais para o saneamento básico, através da incorporação de conselhos populares no processo decisório da administração pública.

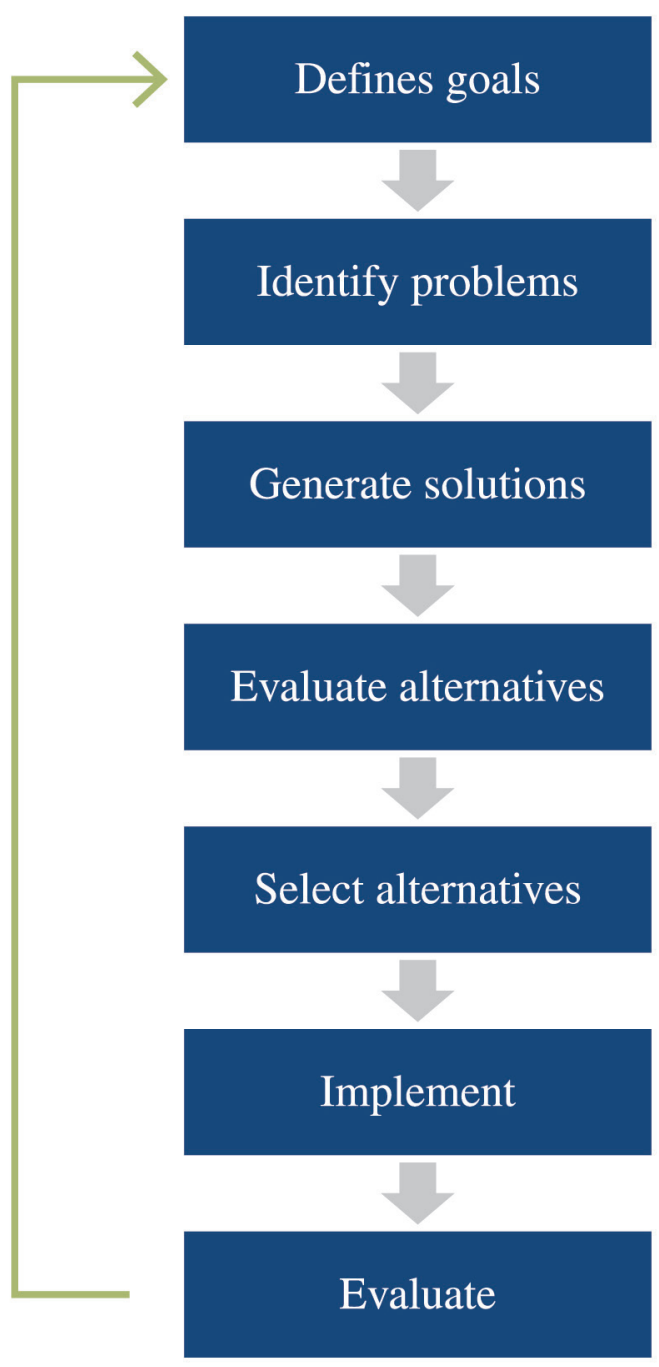

Figura 1 - Processo de planejamento racional Fonte: Ai (2011). 


\section{Gestão municipal participativa}

Wosniak \& Rezende (2012) registram que a gestão é constituída de processos mentais e físicos para estabelecer o desejado e definir quais as formas para se atingir esse cenário. Sob a ótica de Braga (1998), os procedimentos que contribuem para a melhoria da qualidade dos serviços públicos se encontram na gestão participativa. Ouvir, conhecer e discutir as dificuldades, as razões, as diversas maneiras de se tratar um problema e introduzir sugestões colhidas aprimoram os serviços oferecidos à população. A ordem é levantar, divulgar, estruturar e garantir que a decisão tomada seja efetivada. Um instrumento de gestão governamental é o planejamento urbano, seja local ou regional.

Wosniak \& Rezende (2012) destacam a influência que o município pode ter na vida dos cidadãos. Afirmam que a gestão pública requer debate, maior democratização de centros decisórios, flexibilidade nas suas estruturas, nos seus métodos e nos seus processos. Dessa forma, gerir as cidades demanda mudança e criatividade da prática administrativa, com a finalidade de melhorar seu desempenho. Diversas administrações públicas ao redor do mundo convergem para as mesmas preocupações de gestão (Leite \& Rezende, 2010). Os autores recomendam que o gestor público municipal disponha de informações gerenciais e estratégias adequadas para viabilizar o acesso e a melhor prestação dos serviços.

Como uma alternativa na busca para a transposição desses desafios, surgiram, na administração pública, a aplicação de modelos de gestão da iniciativa privada e, também, a utilização de novas tecnologias na transformação e na modernização da gestão pública, inclusive municipal (Leite \& Rezende, 2010, p. 461).

No saneamento básico, a Lei n. 11.445 (Brasil, 2007) revela novas questões que requerem estudos e pesquisas específicos. É imperioso fazer cumprir a lei, cuja discussão tem enfatizado a importância do planejamento, incluindo medidas que fortaleçam os governos locais, por meio de consórcios intermunicipais, além do controle social, o que vai exigir mecanismos de gestão que garantam o poder das autoridades locais e comunidades em um esforço de diálogo e cooperação.
O processo de fortalecimento dos sujeitos nos espaços urbanos pode estar vinculado à predisposição dos governos locais de compartilhar suas decisões, estudos, planos, estimativas e modelos que possam melhorar a gestão municipal.

Há, portanto, a necessidade de considerar o processo de planejamento urbano sob uma outra lógica: de uma noção ligada majoritariamente a simulações, modelos, estimativas, mapas, dados numéricos e estudos substantivos em geral, é forçoso incorporar os aspectos processuais como igualmente importantes e, neles, considerar as limitações cognitivas e seus impactos nos processos decisórios (Saboya, 2013, p. 93).

No processo de estruturação da gestão participativa dos serviços de saneamento básico, diferentes instrumentos de gestão vêm sendo tomados, apresentando graus de adesão diferentes, a depender da compreensão dos atores envolvidos e das respostas às demandas. Dessa forma, partindo da necessidade de estudos substantivos sobre os RSU e da complexidade na tomada de decisões para a adoção de novas práticas de gestão municipal é que se propõe um modelo para a instalação e gestão de equipamentos de destinação final dos RSU. Os estudos voltados para o planejamento urbano, gestão municipal, planejamento estratégico municipal e processos decisórios permitem a transposição desses conceitos para dar suporte à construção do modelo proposto, que, alinhavado ao arcabouço legal do setor, pode proporcionar conhecimentos adicionais e informações para a instalação de novos equipamentos de destinação final dos resíduos sólidos, assim como para o aprimoramento dos já existentes.

\section{Metodologia}

A metodologia adotada foi o estudo multicasos descritivo e exploratório. 0 estudo exploratório teve como finalidade buscar ampliar o conhecimento sobre os serviços de RSU, de modo a garantir familiaridade com o tema e contribuir para a difusão de informações que possam responder algumas questões sobre a gestão e a preservação do meio ambiente. 
O delineamento utilizado se deu por meio da pesquisa bibliográfica e de campo. Quanto aos procedimentos sistemáticos para a descrição e explicação dos eventos encontrados, o estudo se desenvolveu num ambiente que preconizou a abordagem quantiqualitativa.

Para o estudo empírico, foram escolhidos dois aterros sanitários convencionais compartilhados situados no estado da Bahia, um na Região Metropolitana de Salvador (Aterro Metropolitano Centro - AMC) e o outro na Ilha de Itaparica (Aterro Integrado Ilha - AII).

Por meio de tal escolha, foi possível analisar duas áreas com características ambientais distintas, apesar de geograficamente próximas, o que facilitou as visitas de campo. A opção pelos dois aterros também foi motivada pela oportunidade de se estudar diferentes modelos de gestão, pois o AMC é gerido por empresa privada e o AII pelo poder municipal.

Tratou-se de confrontar as ocorrências de variáveis e situações entre os dois equipamentos públicos amostrados, visto que os aspectos quantitativos representam melhor os aterros sanitários. Por outro lado, tem aumentado a preocupação em relação aos aspectos qualitativos de aterros sanitários no estado da Bahia, já que, cada vez mais, esses equipamentos públicos vêm se transformando em vazadouros a céu aberto. Portanto, foram analisados os significados dos eventos ocorridos, de forma crítica, uma vez que apontam tendências quando avaliadas em conjunto.

A pesquisa procurou desenvolver uma cadeia de evidências para explicitar a situação ambiental e a situação de gestão e de gerenciamento dos aterros estudados, apoiadas pela Lei n. 11.445 (Brasil, 2007) e pelo referencial teórico pertinente ao planejamento urbano e à gestão municipal.

Os trabalhos se dividiram em dois blocos principais: o primeiro, referente à caracterização ambiental das áreas onde estão implantados os aterros sanitários selecionados; o segundo bloco de investigação esteve ligado à gestão desses aterros sanitários, integrando-a ao conhecimento adquirido pelo referencial teórico adotado.

As informações espaciais e os materiais de interesse para este trabalho, assim como dados dos processos gerenciais e de gestão, foram levantados durantes as visitas aos aterros sanitários em estudo. Para a pesquisa de campo, elaborou-se um roteiro de consulta, visando retratar a situação ambiental e de gestão das áreas de destinação final dos RSU. A pesquisa de campo resultou também em um registro fotográfico acompanhado de anotações.

\section{Apresentação de um modelo alternativo para a gestão de aterros sanitários}

Em muitas ocasiões, não é possível dar uma resposta definitiva a antigos e difíceis problemas. Entretanto, existe a possibilidade de se fornecer um delineamento teórico, por meio de um modelo que adote a visão do conjunto, ou seja, observando-se diferentes variáveis e construindo-se um esquema com um alcance analítico aplicável às particularidades de cada município.

O modelo para implantação de aterros sanitários proposto nesse trabalho leva em consideração as dificuldades de recursos enfrentadas pelos municípios baianos e está apoiada em quatro pressupostos:

1. Diagnóstico, planejamento, implantação e gestão do aterro sanitário a cargo do poder público.

2. Desconhecimento da população dos prejuízos ambientais causados pela disposição inadequada dos RSU, o que dificulta a participação e controle popular no sistema público de limpeza urbana.

3. Qualificação insuficiente de recursos humanos nos municípios, impedindo a prática dos conceitos ligados à gestão ambiental.

4. Utilização de alguns dispositivos contidos na Lei n. 11.445 (Brasil, 2007), como o da Gestão dos Serviços Públicos de Saneamento Básico, que contempla as funções de planejamento, regulação, prestação dos serviços e fiscalização, com o controle social transversal a todas elas.

Com base nos pressupostos anteriormente apresentados, o modelo teórico para Instalação e Gestão de Equipamentos de Destinação Final dos Resíduos Sólidos foi concebido como uma proposta alternativa e mais abrangente do que os atuais modelos técnico-operacionais, mais conhecidos e disseminados pela bibliografia nacional. Os aspectos 
ambientais e de gestão devem ser levados em consideração.

Em termos gerais, a perspectiva ambiental se constitui em programas educacionais na área do meio ambiente, licenciamento ambiental e controle dos impactos socioambientais. Na vertente de gestão, de forma mais ampla, considera-se diagnóstico, modelo de gestão do equipamento, elaboração de planos das ações e captação de recursos, implantação do equipamento, capacitação técnica e de gestão, instalação de equipamentos de apoio e avaliação periódica dos trabalhos e dos resultados.

A Figura 2 apresenta o fluxograma da proposta de modelo, evidenciando que a sua estrutura, que inclui os tipos de atividades e suas interações, pode ser válida para qualquer município, seja de pequeno, médio ou grande porte.

\section{Definição das atividades do modelo}

Na sequência, serão apresentadas as atividades propostas para o modelo desenvolvido.

Todo o processo de implantação de um aterro sanitário deverá estar fundamentado no diagnóstico da situação da destinação dos resíduos sólidos. Esse levantamento deverá ser realizado pelo poder público. Com base nesse documento, considerando os dispositivos da legislação vigente, os órgãos competentes definirão a necessidade de instalação de um novo equipamento ou de recuperação do existente. No caso de recuperação de aterros existentes, deverão ser seguidos os procedimentos e legislações próprias para atividades potencialmente poluidoras.

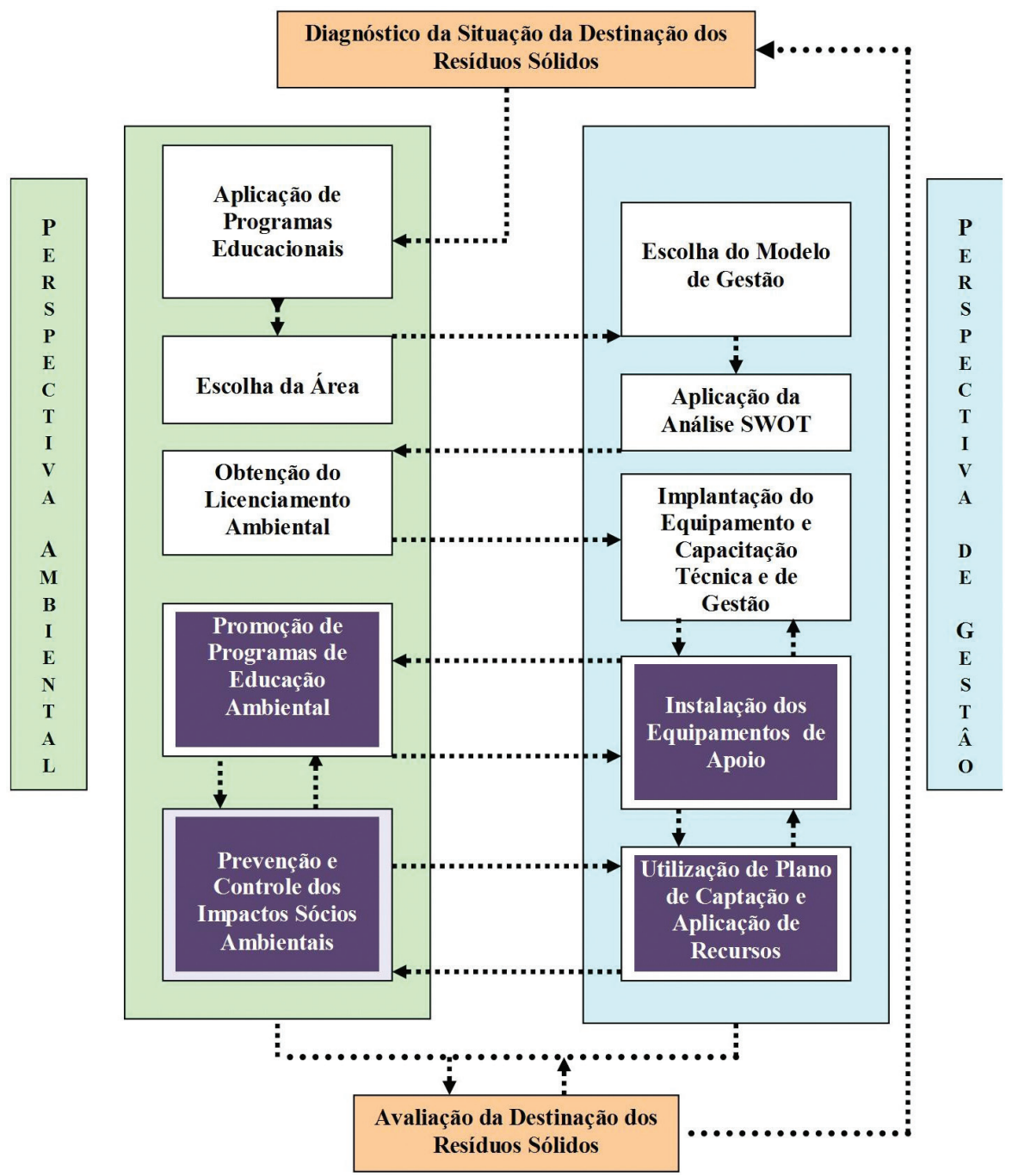

Figura 2 - Modelo para Instalaç̃̃o e Gestão de Equipamentos de Destinaccão Final dos Resíduos Sólidos Fonte: Marchi (2011). 
Para a outra situação, apresenta-se o modelo proposto neste trabalho. É importante salientar que, antes de iniciar a instalação de um equipamento de destinação final, recomenda-se realizar programas educacionais sobre meio ambiente, a fim de conscientizar a população local, tornando-a agente transformador da sua realidade socioambiental. Dando prosseguimento ao processo, as áreas selecionadas para a implantação do equipamento deverão ser apresentadas à população, visando escolha da área, onde será observada a caracterização dos processos do meio físico, atuantes no ambiente selecionado, bem como na previsão das alterações a que esses processos estão sujeitos, em face da instalação e funcionamento de um aterro sanitário.

Definida a área com a comunidade impactada pelo equipamento, o próximo passo é a escolha do tipo de gestão mais adequada, que deverá ser feita pelo poder público. Se gestão regionalizada, por meio de gestão privada, parcerias públicoprivadas, gestão pública, gestão interinstitucional, sob a forma de consórcios, redes ou parcerias. Ao final da escolha do tipo de gestão a ser aplicada no aterro, é recomendável a análise $\boldsymbol{S W O T}^{1}$ do futuro equipamento, ou seja, o levantamento dos pontos fortes e fracos, oportunidades e ameaças inseridos no modelo de gestão escolhido.

A próxima etapa é o processo de licenciamento ambiental, que pode se desenvolver por meio da licença de localização, licença de implantação e licença de operação. Cada fase de licenciamento deve ser intercalada com capacitação técnica $\boldsymbol{e}$ de gestão para o pessoal envolvido no sistema de limpeza urbana do município ou dos municípios participantes. Os municípios reconhecem que não possuem técnicos capacitados para a elaboração de trabalhos dessa natureza ou verba para contratação de profissionais para tal fim.

Barbosa et al. (2010) corroboram com a ideia que o pessoal lotado nos órgãos ligados à área de saneamento básico dos municípios baianos necessita de treinamento e capacitação técnica. Apresentam

\footnotetext{
1 Análise SWOT (Strengths, Weakness, Oppotunites e Threats) é uma técnica inserida no planejamento estratégico das organizações que discute quais as posições internas a serem tomadas diante das forças e fraquezas que agem contra ou a favor dos interesses da organização, e quais são as posições externas que devem ser reforçadas ou evitadas. No caso deste modelo, tomou-se como base a proposta de planejamento estratégico municipal (PEM).
}

os resultados obtidos pela Pesquisa de Tecnologias de Gestão, que demonstram a falta de sensibilidade de atendimento ao público por parte dos gestores dos serviços públicos de saneamento básico. Intermitência no fornecimento de serviços públicos de saneamento básico nos bairros periféricos e ausência de acesso da população de baixa renda à educação são problemas encontrados nos municípios pesquisados. Questões como participação e controle social, prestação de contas à sociedade, ferramentas de gestão e avaliação das ações contidas no Capítulo IV - Do Controle Social - inserido no Decreto $n$. 7.217 (Brasil, 2010a), muitas vezes, são ignoradas ou deixadas em segundo plano. Por outro lado, a amostra total levantada pela pesquisa, aproximadamente $70 \%$ da população dos municípios pesquisados acreditam que o saneamento básico é um dos três principais problemas existentes no seu município, sendo que $33 \%$ afirmam que o principal problema enfrentado no seu dia a dia é a ausência de serviços públicos de abastecimento de água, esgotamento sanitário e da coleta e da destinação adequada dos resíduos sólidos.

É necessária a construção de uma nova forma de pensar e agir, envolver as ações de serviços públicos de saneamento básico com a prática da cidadania. Nessa direção, alguns equipamentos de apoio instalados nas zonas urbanas dos municípios são importantes, tais como: maquinários relacionados à reciclagem e reuso dos resíduos sólidos, veículos, contêineres, dentre outros. Esses equipamentos devem ser utilizados na coleta porta a porta, em estação de transbordo, em unidades de triagem ou de compostagem, em pontos de entrega voluntária (PEV), em postos de reaproveitamento e, ainda, por cooperativas habilitadas para coletar os resíduos sólidos, dentre outros.

A partir daí, é iniciada uma nova etapa no modelo, ou seja, uma etapa cíclica, orientada para a utilização de novas técnicas, educação permanente, controle de impactos socioambientais, captação e aplicação de recursos. Essa dinâmica dialética busca transformar a realidade, a partir de ações recorrentes e recursivas, que contêm práticas ambientais, pedagógicas, de regulação e de gerenciamento, interagindo umas com as outras. A redução, a reutilização e a reciclagem “3 R" pressupõem atenção preponderante ao ser humano. A educação insere-se na dinâmica da aprendizagem, a partir da concepção de que é o homem o principal protagonista do processo de 
separação dos resíduos sólidos na origem, quando passa de uma posição passiva para um papel ativo.

Portanto, a educação é foco de atenção especial para o processo de gestão ambiental. A segunda etapa de programas educacionais proposta por este trabalho terá como público alvo tanto a comunidade quanto as pessoas envolvidas na gestão e operação do aterro, visando atender aos "3 R" e criar consciência e responsabilidade ambientais. Os conhecimentos a serem fornecidos devem abranger diferenciados valores e tomadas de decisões, que englobem o desenvolvimento de potencialidades e de possibilidades, para informação e convencimento da comunidade sobre os benefícios das ações de redução dos resíduos sólidos. 0 objetivo principal desta segunda etapa educacional é sensibilizar e estimular a consciência sobre a necessidade da limpeza do município e incentivar iniciativas que busquem diminuir a geração pessoal e coletiva de resíduos sólidos.

A prevenção e o controle dos impactos sociais e ambientais reúnem a observação e a mensuração de todas as ações e medidas anteriores, reexaminando os avanços e limitações. Na última fase desta etapa cíclica se encontra o plano de captação de recursos, que identifica cada componente de apoio ao processo e garante a adequada aplicação dos recursos para os fins para os quais foram captados.

Encerrando o processo do modelo de instalação e gestão de um aterro sanitário, se deve proceder a uma avaliação periódica dos trabalhos e dos resultados e, com base nesta avaliação, se deve determinar um conjunto de ações a serem desenvolvidas, com cronograma de execução. Esse cronograma detalha, ao máximo, cada uma das ações previstas para o próximo período, bem como os responsáveis por sua execução. Essa atividade, a depender dos resultados encontrados, realimentará um novo diagnóstico sobre a situação da destinação dos resíduos sólidos no município, contribuindo para a tomada de decisões nos programas de ajuste das dificuldades encontradas.

O modelo sugerido se constitui em um instrumento de análise, que busca evitar futuros problemas e viabilizar soluções. Esse modelo pode contribuir para a construção de um caminho possível em atendimento equânime e universal de serviços públicos de saneamento básico.

\section{Considerações finais}

Não obstante o sucesso da promulgação da lei federal em 2010, embora certos aterros sanitários possam estar de fato sendo adequadamente gerenciados, os resíduos sólidos do estado da Bahia ainda não têm destino final apropriado. Como as condições gerais de urbanização das cidades não se modificam na mesma velocidade, presume-se que mais da metade dos resíduos sólidos seja descartada em qualquer parte: nas estradas, nas matas, nos rios, nas esquinas.

O estudo sobre os aspectos ambientais em aterros sanitários comprovou que quando o estado resolve instalar um equipamento de destinação final, vem aplicando, na maioria das vezes, corretos fundamentos técnicos e geológicos. Mas é durante o processo de operacionalização e gestão desses equipamentos que começam as dificuldades e carências de recursos humanos, técnicos, operacionais e financeiros, transformando o equipamento apropriado em vazadouro a céu aberto.

A Política Nacional de Resíduos Sólidos reúne o conjunto de princípios, objetivos, instrumentos, diretrizes, metas e ações adotados pelo governo federal, isoladamente ou em regime de cooperação com estados, Distrito Federal, municípios ou particulares, com vistas à gestão integrada e ao gerenciamento ambientalmente adequado dos resíduos sólidos. Mas essa norma, por si só, não será capaz de modificar a realidade dessa área no Brasil.

Para se atingir os objetivos propostos pela Política Nacional de Resíduos Sólidos é necessário o cumprimento de disposições legais, tais como:

i) tornar permanentes as linhas de Educação Ambiental Pública, Formal, de Comunidades e de Empresas;

ii) observar, na pré-seleção das áreas para instalação de aterros sanitários, alguns atributos do meio físico que indiquem de forma segura as áreas viáveis ao empreendimento;

iii) escolher o tipo de equipamento mais adequado para a destinação final dos resíduos sólidos;

iv) obter Licenciamento Ambiental;

v) capacitar técnica e gerencialmente a equipe envolvida com o equipamento público; 
vi) diversificar os equipamentos, ferramentas e tecnologias que complementem a sustentabilidade do equipamento público;

vii) respeitar uma hierarquia de gestão dos resíduos sólidos que priorize: evitar a geração; minimizar a geração; reaproveitar os resíduos sólidos inevitavelmente gerados; tratar; e dispor os rejeitos de forma ambientalmente adequada;

viii) controlar os inevitáveis impactos socioambientais.

A elaboração de plano municipal de gestão integrada de resíduos sólidos, nos termos previstos pela lei que institui a Política Nacional de Resíduos Sólidos, é condição para o Distrito Federal e os municípios terem acesso a recursos da União. Mas, como poderão ser esses planos elaborados e executados, se muitas vezes, nos municípios, principalmente os de pequeno porte, não existe pessoal capacitado para analisar e ter acesso às exigências legais? Uma grande parte do pessoal técnico municipal não está preparada para indicar os meios para minimizar os impactos negativos ocasionados pelas formas de uso, costumes e hábitos culturais relativos aos resíduos sólidos dos municípios. Compete ao poder público fomentar, organizar e educar em vez de prover, intervir e assistir, como vem acontecendo ao longo das últimas décadas.

A pergunta norteadora deste trabalho foi se o desenvolvimento de um modelo para instalação de equipamentos de destinação final dos resíduos sólidos, que envolvesse aspectos ambientais e de gestão, poderia atender as especificidades, particularidades, de diferentes municípios. A realização deste trabalho proporcionou um maior entendimento do tema, o que permitiu concatenar as práticas ambiental e de gestão, que vêm sendo utilizadas em diferentes partes do estado da Bahia, com novas práticas de planejamento urbano e gestão municipal, favorecendo assim a elaboração do modelo proposto que atende municípios diversos. A proposição feita por meio deste modelo busca ainda proporcionar informações que podem servir de auxílio ao aprimoramento dos equipamentos já existentes.

Considerar que resultados positivos e duradouros podem ser obtidos por meio da integração entre serviços públicos e cidadania. As prioridades máximas para qualquer modelo devem estar apoiadas na coleta de todos os resíduos sólidos municipais, na promoção de uma destinação adequada e na busca de novas tecnologias e formas de manejo para os resíduos sólidos dos municípios, sempre apoiadas pela participação cidadã.

Tratou-se, enfim, de um processo de construção teórica e metodológica que partiu de perguntas e gerou novas questões, especialmente quanto à forma de mensurar e analisar possíveis mudanças comportamentais em saneamento básico, em função das posturas e procedimentos inovadores difundidos em todo o país pela Política Nacional de Resíduos Sólidos.

\section{Referências}

Ai, N. (2011). Challenges of sustainable urban planning: the case of municipal solid waste management (Dissertação de mestrado). GeorgiaInstituteof Technology, Georgia. Recuperado em 16 de agosto de 2014, de https:// smartech.gatech.edu/bitstream/handle/1853/44926/ ai_ning_201108_phd.pdf?sequence=1.

Barbosa, A. M. G., Marchi, C. M. D. F., \& Mendes, V. L. S. (2010). A Participação Cidadã na Gestão dos Serviços Públicos de Saneamento: Os Gestores e a Sociedade Civil Dialogam? In Anais do III Seminário Nacional e I Seminário Internacional Movimentos Sociais Participação e Democracia (1 CD ROM). Florianópolis: UFSC.

Braga, D. G. (1998). Conflitos, eficiência e democracia na gestão pública. Rio de Janeiro: Editora FIOCRUZ. Recuperado em 06 de agosto de 2014, de http://books. scielo.org.

Brasil (1979, 19 de dezembro). Lei n. 6.766, de 19 de dezembro de 1979. Dispõe sobre o Parcelamento do Solo Urbano e dá outras Providências. Brasília: Diário Oficial da União. Recuperado em 06 de abril de 2014, de http:// www.planalto.gov.br/ccivil_03/leis/16766.htm.

Brasil (1981, 31 de agosto). Lei n. 6.938, de 31 de agosto de 1981. Dispõe sobre a Política Nacional do Meio Ambiente, seus fins e mecanismos de formulação e aplicação, e dá outras providências. Brasília: Diário Oficial da União. Recuperado em 06 de abril de 2014, de http://www. planalto.gov.br/ccivil_03/leis/16938.htm.

Brasil (1988). Constituição da República Federativa do Brasil de 1998. Brasília: Diário Oficial da União. 
Brasil (1993, 31 de agosto). Resolução Conama n. 5, de 05 de agosto de 1993. Dispõe sobre o gerenciamento de resíduos sólidos gerados nos portos, aeroportos, terminais ferroviários e rodoviários. Brasília: Diário Oficial da União, seção 1. Recuperado em 20 de novembro de 2014, de http://www.mma.gov.br/port/conama/legiabre. cfm?codlegi $=130$.

Brasil (2001, 11 de julho). Lei n. 10.257, de 10 de julho de 2001. Regulamenta os arts. 182 e 183 da Constituição Federal, estabelece di $\neg$ retrizes gerais da política urbana e dá outras providências. Brasília: Diário Oficial da União. Recuperado em 20 de novembro de 2014, de http://www. planalto.gov.br/ccivil_03/leis/leis_2001/110257.htm.

Brasil (2007, 05 de janeiro). Lei n. 11.445, de 05 de janeiro de 2007. Estabelece diretrizes nacionais para o saneamento básico; e dá outras providências. Brasília: Diário Oficial da União. Recuperado em 06 de março de 2013, de http:// www.planalto.gov.br/ccivil_03/_ato2007-2010/2007/ lei/l11445.htm.

Brasil (1998, 12 de fevereiro). Lei n. 9.605, de 12 de fevereiro de 1998. Dispõe sobre as sanções penais e administrativas derivadas de condutas e atividades lesivas ao meio ambiente, e dá outras providências. Brasília: Diário Oficial da União. Recuperado em 25 de novembro de 2014, de http://www. planalto.gov.br/ccivil_03/leis/19605.htm

Brasil (2010a, 22 de junho). Decreto n. 7.217, de 21 de junho de 2010. Regulamenta a Lei 11.445, de 5 de janeiro de 2007, que estabelece diretrizes nacionais para o saneamento básico, e dá outras providências. Brasília: Diário Oficial da União. Recuperado em 20 de novembro de 2014, de http:// www.planalto.gov.br/ccivil_03/_ato2007-2010/2010/ Decreto/D7217.htm.

Brasil (2010b, 23 de dezembro). Decreto n. 7.404, de 23 de dezembro de 2010. Regulamenta a Lei no 12.305, de 2 de agosto de 2010, que institui a Política Nacional de Resíduos Sólidos, cria o Comitê Interministerial da Política Nacional de Resíduos Sólidos e o Comitê Orientador para a Implantação dos Sistemas de Logística Reversa, e dá outras providências. Brasília: Diário oficial da União. Recuperado em 25 de novembro de 2014, de http://www.planalto.gov. br/ccivil_03/_ato2007-2010/2010/Decreto/D7404.htm.
Brasil (2010c, 02 de agosto). Lei n. 12.305, de 02 de agosto de 2010. Institui a Política Nacional de Resíduos Sólidos; altera a Lei no 9.605, de 12 de fevereiro de 1998; e dá outras providências. Brasília: Diário Oficial da União. Recuperado em 06 de fevereiro de 2011, de http://www.planalto.gov. br/ccivil_03/_ato2007-2010/2010/lei/112305.htm.

Brasil (2014a, 21 de março). Decreto n. 8.211, de 21 de março de 2014. Altera o Decreto n. 7.217, de 21 de junho de 2010, que regulamenta a Lei $n$. 11.445, de 5 de janeiro de 2007, que estabelece diretrizes nacionais para o saneamento básico. Brasília: Diário oficial da União. Recuperado em 25 de novembro de 2014, de http://www.planalto.gov. br/ccivil_03/_Ato2011-2014/2014/Decreto/D8211.htm.

Brasil (2014b, 14 de janeiro). Lei n. 12.932, de 07 de janeiro de 2014. Institui a Política Estadual de Resíduos Sólidos, e dá outras providencias. Bahia: Diário Oficial do Estado. Recuperado em 06 de abril de 2014, de http:// concidadesba.blogspot.com.br/2014/01/blog-post.html.

Leite, L. O., \& Rezende, D. A. (2010). Modelo de gestão municipal baseado na utilização estratégica de recursos da tecnologia da informação para a gestão governamental: formatação do modelo e avaliação em um município. Revista de Administração Pública, 44(2), 459-493. http:// dx.doi.org/10.1590/S0034-76122010000200012.

Marchi, C. M. D. F. (2011). Ecogerenciamento: aspectos das características geológicas e de gestão na construção de um modelo para instalação de aterros sanitários no estado da Bahia (Tese de doutorado). Universidade Federal da Bahia, Salvador.

Moraes, L. R. S., \& Borja, P. C. (2009). Gestão integrada e sustentável e tecnologias apropriadas para manejo de resíduos sólidos urbanos - um outro paradigma. In Anais do III Congreso Interamericano de Resíduos Sólidos de AIDIS (1 CD ROM). Buenos Aires: AIDIS.

Nunesmaia, M. F. A. (2002). Gestão de resíduos urbanos e suas limitações. Revista Baiana de Tecnologia, 17(1), 120-129.

Pfeiffer, P. (2000). Planejamento estratégico municipal no Brasil: uma nova abordagem. Brasília: Enap.

Saboya, R. T. (2013). Fundamentos conceituais para uma teoria do planejamento urbano baseada em decisões.urbe, Revista Brasileira de Gestão Urbana, 5(2), 81-95. http:// dx.doi.org/10.7213/urbe.05.002.AC01. 
Syndicat Intercommunal Traitement Des Ordures Menageres L'agglomeration Parisienne - SYCTOM (2008).

Traiter vos déchets. Recuperado em 04 de abril de 2008, de http://www.syctom-paris.fr/edi/syct/syctom.htm.

United Nations Environment Programme - UNEP \& International Environmental Technology Centre - IETC (2005). Solid Waste Management (Regional Overviews and Information Sources, Vol. 2). Local: United Nations Environment Programme Dez.
United States Environmental ProtectionAgency - USEPA (1996). It's easy being green! A guide to planning and conducting environmentally aware meetings and events (Solid Waste and Emergency Response). Washington: USEPA.

Wosniak, F. L., \& Rezende, D. A. (2012). Gestão de estratégias: uma proposta de modelo para os governos locais. Revista de Administração Pública, 46(3), 795-816. http://dx.doi.org/10.1590/S0034-76122012000300009.

Recebido: Jun. 11, 2014

Aprovado: Set. 3, 2014 